\title{
Analysis of Engineering Students' Responses to Flipped Classroom Methodology in the United Arab Emirates
}

\author{
Majed $\operatorname{Khodr}^{1} \&$ Lee Waller ${ }^{2}$ \\ ${ }^{1}$ School of Engineering, American University of Ras Al Khaimah, Ras Al Khaimah, United Arab Emirates \\ ${ }^{2}$ School of Arts \& Sciences, American University of Ras Al Khaimah, Ras Al Khaimah, United Arab Emirates \\ Correspondence: Majed Khodr, School of Arts \& Sciences, American University of Ras Al Khaimah, PO Box \\ 10021, Ras Al Khaimah, United Arab Emirates. Tel: 971-56-156-5977. E-mail: majed.khodr@aurak.ac.ae
}

\author{
Received: November 22, 2015 Accepted: December 16, 2015 Online Published: January 12, 2016 \\ doi:10.5539/ass.v12n2p93 \\ URL: http://dx.doi.org/10.5539/ass.v12n2p93
}

\begin{abstract}
The aim of this study was to analyse student responses to the introduction of flipped learning methodology at an institution of higher education in the northern region of the United Arab Emirates to identify potential relationships between and among the responses and to determine underlying factors guiding the responses. A survey questionnaire was developed by a team of faculty and sent to students via online survey software. The analysis employed dimension reduction techniques to ascertain underlying factors guiding responses. Two major factors were identified: (1) the focus on educational benefits of the methodology and (2) the instructional relevance of the flipped classroom approach. The study concluded that flipped learning methodology can be useful for improving learning and holds the potential to more adequately engage today's learners.
\end{abstract}

Keywords: flipped classroom, communication, higher education, creativity, United Arab Emirates

\section{Introduction}

The intent of flipped classroom methodology is to transition from the traditional instructional paradigm to a more dynamic technologically based didactic approach. Flipped learning reverses the traditional order of the classroom to engage students in learning materials outside the classroom via technology. Flipped learning then engaging students in working together on project/problem based learning during traditional class meetings. The flipped classroom is founded on learning procedures that are reflexive, shared, and connected with the modern availability of massive amounts of information. The flipped classroom model is also one of several emerging, creative ideas utilized by large numbers of universities all around the world. The flipped classroom is a new way of teaching which moves beyond traditional methodologies to engage learners at a higher level (Lumadue, Waller, Hendricks, \& Lumadue, 2012).

\section{Review of the Literature}

The flipped classroom seems to be catching on with higher education. According to the Flipped Learning Network (2013), flipped learning is particularly well suited to higher education settings for a variety of reasons. The in-class discussion and enrichment activities allowed by moving content delivery outside of class time provide opportunities for students to develop vital skills needed in the 21 st century. Flipped classroom methodology holds students to a higher level of academic expectations by requiring team-based and peer-to-peer interaction. Flipped learning is a relatively new model for both public and higher education and, as such, challenges pervade its implementation. These challenges can be issues such as course redesign, teaching load, student acceptance, and student evaluation (Fisher \& Waller, 2013).

Studies on the efficacy of flipped learning at the higher education level are few and far between; however, some preliminary examinations suggest that flipping the classroom may produce benefits such as improving student-teacher interaction (Hamre \& Pianta, 2005), providing opportunity for real time feedback (Greenberg, Medlock, \& Stephens, 2011), increasing the depth of student engagement (Medina, 2008), empowering self-paced learning (Hattie, 2008), and adding meaning to course assignments (Beesley \& Apthorp, 2010).

Hamre and Pianta (2005) found that teachers who recognize and respond to students' social and emotional needs are as important to academic development as specific instructional practices. This was especially true for at-risk students. Greenberg, Medlock and Stephens (2011) found that flipped learning methodology provided greater 
opportunity for the teacher to spend more one-to-one time with students than in the traditional classroom. These researchers asserted that this additional time with students provided the opportunity to provide more real time feedback and immediately correct student misperceptions. Medina (2008) found that online lectures more adequately address the way in which today's learners process information. Online lectures allow continued review of the instructional materials until the subject has been mastered. Additionally, lectures can be broken down into smaller bites to enhance recall of materials. Hattie (2008) found that flipped learning empowered self-paced learning with student access to subsequent lectures and lessons. Beesley and Apthorp (2010) found that specific, in-class opportunities for students to practice their skills with immediate feedback had a much greater impact on student learning. Accordingly, class assignments took on greater meaning and importance.

Fisher and Waller (2013) indicate that numerous technologies can be utilized to "flip" a class. The following technologies are only a sample of the technologies that can be utilized to make and present online substance, lessons, evaluations, and criticism. Cooperation devices can be utilized both as a part of class and outside of class for gathering tasks, engaging critical thinking and sharing assets, contingent upon the instructional exercises (Waller \& Lumadue, 2011). Some examples follow though the list is by no means exhaustive (University of Southern California, 2015).

1. Writing board course site (appraisals, course substance, gathering activities and then some)

2. Lecture catch devices: room-based (Media Site, studio classrooms) and desktop (Camtasia, Adobe Presenter)

3. Video recording and modification (webcam, cam, iMovie)

4. Annotation/remarking (VoiceThread)

5. Collaboration devices (Google Docs)

6. Polling and study apparatuses (TurningPoint)

7. Videoconferencing (Skype, GoToMeeting, Google Circles)

8. Mobile gadgets for venture based exercises (tablets, phones).

\section{Research Methodology}

The study was designed to survey the understanding of the flipped classroom methodology by students within the School of Engineering and to identify potential relationships and to determine the underlying factors guiding the responses. To establish content validity, a team of four faculty members was utilized to develop a brief, 7-item survey intended to examine student views regarding the flipped classroom methodology. The first six questions scored answers according to a 5-point Likert scale from strongly agree (5) to strongly disagree (1). Question 7 had only three possible answers: short - less than 10 minutes (3), medium - more than 10 minutes but less than 20 minutes and long - more than 20 minutes (1). The faculty team also included an open-ended section into which participants could enter any comments deemed germane to the responses on the questionnaire. The instrument was administered via online methodology to a set of 300 selected students representing the institution's School of Engineering. The survey garnered 50 individual responses. This is a response rate of $16.7 \%$. A Chronbach Alpha was utilized to establish the reliability of the responses and returned a score of .848, which falls above the minimum threshold of .70 (Lumadue \& Waller, 2013).

The study examined two research questions.

1. What are the School of Engineering student responses to the flipped classroom survey?

2. Do relationships exist within the School of Engineering student responses to the flipped classroom survey?

Research question 1 was answered by descriptive analysis and did not require the development of research hypotheses. The following two research hypotheses were utilized to examine research question 2 .

Ho: No relationships exist within the School of Engineering student responses to the flipped classroom survey.

Ha: Relationships exist within the School of Engineering student responses to the flipped classroom survey.

Survey response descriptives were collected in answer to research question 1. Bartlett's test of sphericity was utilized to examine the research hypotheses associated with research question 2. Critical values were established at the standard range of .05. Once a relationship was established, dimension reduction (factor analysis) was utilized to examine for factors underlying the identified relationship. The study utilized principle component as the extraction method and employed a varimax rotation with Kaiser normalization. Eigenvalues having scores above 1.0 were deemed significant. The protocols for dimension reduction were examined, and the 
Kaiser-Meyer-Olkin measure was employed to examine sampling adequacy. Dimension reduction was deemed an appropriate research methodology to examine underlying factors guiding responses on a survey instrument as long as the appropriate research protocols were established (Waller \& Lumadue, 2013). All associated findings are discussed in the analysis of research question 2 .

\section{Research Findings}

The survey instrument was administered in Fall 2015 to 300 students enrolled in the School of Engineering at one institution of higher learning in the northern most section of the United Arab Emirates. The survey was sent to students three times over a period of four weeks to obtain the highest possible response rate. Once the survey was responded to, no student could enter a second time to record another response. After the responses were obtained, all identifying information was removed to protect the anonymity of the respondents.

\subsection{Research Question 1}

Research question 1 inquired as to the School of Engineering student responses to the flipped classroom survey. In response to research question 1, descriptive analysis was conducted to determine the number, mean, and standard deviation for the responses to each question. Findings are provided in Table 1.

Table 1. Question responses on the fall 2015 flipped classroom survey

\begin{tabular}{lccc}
\hline Question & N & Mean & Standard Deviation \\
\hline $\begin{array}{l}\text { 1. Would you say that you have knowledge about flipped classrooms? } \\
\text { 2. Do you think that implementing flipped classrooms would help you } \\
\text { get better grades? }\end{array}$ & 50 & 3.86 & 1.030 \\
$\begin{array}{l}\text { 3. Do you think that problem solving and discussion in class, would } \\
\text { keep the class from being boring? }\end{array}$ & 50 & 4.08 & .857 \\
$\begin{array}{l}\text { 4. Do you think the idea of flipped classrooms would make the } \\
\text { learning process more fun? }\end{array}$ & 50 & 4.32 & .867 \\
$\begin{array}{l}\text { 5. Do you think that implementing flipped classrooms would ease the } \\
\text { pressure of missing the lecture? }\end{array}$ & 50 & 4.38 & .780 \\
$\begin{array}{l}\text { 6. Do you think it would be an improvement for XYZ University to } \\
\text { implement flipped classrooms? }\end{array}$ & 50 & 4.44 & .760 \\
$\begin{array}{l}\text { 7. If you were required to watch videos of the lecture, what do you } \\
\text { prefer the length of the video to be? }\end{array}$ & 50 & 1.98 & .589 \\
\hline
\end{tabular}

Findings ranged from a high of 4.44 on question 6 to a low of 3.86 on question 1 excluding question 7 . These responses indicate a mean response rate ranging from strongly agree to agree for all six survey questions. The scale utilized for question 7 differed from the scale utilized on question 1 through question 6 . The score on question 7 indicates a preference for medium length videos. Medium length was defined to be between 10 and 20 minutes in length.

\subsection{Research Question 2}

Prior to the examination of the research hypotheses associated with research question 2, the study examined the adequacy of the sample size and established the requirements of the data set. The Kaiser-Meyer-Olkin measure of sampling adequacy was .673, which falls into an acceptable range. Dimension reduction requires that the data set have more variables than identified underlying factors (Waller \& Lumadue, 2013). The data set conformed with this expectation.

The Bartlett's test of sphericity was utilized to ascertain the existence of relationships within the responses to the survey instrument. Bartlett's test of sphericity indicated significance $<.001$. Accordingly, the null hypothesis-Ho was rejected in favour of the alternate hypothesis-Ha. Relationships were found to exist within the School of Engineering student responses to the flipped classroom survey. The identified relationships were then examined with dimension reduction techniques utilizing a principle component extraction. The findings follow in Table 2 . 
Table 2. Total variance explained

\begin{tabular}{ccccccc}
\hline \multirow{2}{*}{ Component } & \multicolumn{3}{c}{ Initial Eigenvalues } & \multicolumn{3}{c}{ Rotation Sums of Squared Loadings } \\
& Total & \% Variance & Cumulative \% & Total & \% Variance & Cumulative \% \\
\hline 1 & 2.935 & 41.931 & 41.931 & 2.762 & 39.457 & 39.457 \\
2 & 1.297 & 18.535 & 60.466 & 1.471 & 21.009 & 60.466 \\
\hline
\end{tabular}

Note. Extraction Method: Principle Component Analysis

Findings identified two major factors underlying student responses to the questionnaire. Examination of the rotation sums of squared loadings indicated that these two identified factors accounted for $60.466 \%$ of the variance within the data set. Viewed conversely this means that $39.534 \%$ of the variance was not explained. Factor I accounted for the highest portion at 39.457\% while Factor II accounted for $21.009 \%$. The factor loadings were extracted utilizing a varimax rotation. Factor loadings of more than .4 were considered significant (Waller \& Lumadue, 2013). The factor loadings follow in Table 3.

Table 3. Component matrix

\begin{tabular}{lcc}
\hline Question & Component \\
\hline 1. Would you say that you have knowledge about flipped classrooms? & $\mathbf{1}$ & $\mathbf{2}$ \\
2. Do you think that implementing flipped classrooms would help you get better grades? & .721 & .241 \\
3. Do you think that problem solving and discussion in class, would keep the class from being & .810 & -.058 \\
$\quad$ boring? & .232 & .742 \\
4. Do you think the idea of flipped classrooms would make the learning process more fun? & .818 & .209 \\
$\begin{array}{l}\text { 5. Do you think that implementing flipped classrooms would ease the pressure of missing the } \\
\text { lecture? }\end{array}$ & .576 & -.082 \\
$\begin{array}{l}\text { 6. Do you think it would be an improvement for XYZ University to implement flipped } \\
\text { classrooms? }\end{array}$ & .725 & .192 \\
7. If you were required to watch videos of the lecture, what do you prefer the length of the video \\
to be?
\end{tabular}

Extraction Method: Principle Component Analysis - Rotation Method: Varimax with Kaiser Normalization

Rotation converged in 3 iterations

Analysis of the component matrices led the researcher to identify and name the two factors underlying responses to the survey as (1) the focus on educational benefits of the methodology and (2) the instructional relevance of the flipped classroom approach. Factor 1 focused on the educational advantages that the respondents associated with the flipped classroom methodology. Factor 2 only involved questions 3 and 7 . These questions related to maintaining student interest and views regarding the appropriate length of instructional video.

Survey participants provided 26 comments that they deemed germane to the responses on the questionnaire. Comments were both positive and negative though the positive were more predominant.

The positive comments expounded advantages to the utilization of flipped learning. Respondents viewed the concept as a successful means of managing time and fostering creative thinking. Advantages were also noted in having the opportunity to watch and re-watch instruction videos until concepts were mastered. Several noted the importance of being able to take notes by watching and rewatching the videos slowly. Participants noted that more time was available to actually focus on the problem sets while the videos could be watched at their leisure. One of the most common themes centered on the flexibility of the model to meet their varied life and work schedules.

The negative comments can be summed up with two major themes. First, some respondents felt that classes should focus more on lecture and leave practice for the students to complete outside of class. Second, concern was voiced that discussions and problem solving occur when the concept is being taught.

\section{Conclusions and Implications}

Analysis of the findings indicates that the students held a positive impression of flipped classroom methodology. 
The mean score for question 6 was 4.44. This indicates that responses fell between the strongly agree and agree range in regard to the perception that the implementation of flipped classrooms would be an improvement for the institution. The identification of the two underlying factors guiding the responses further indicates that the respondents view the flipped classroom methodology as holding educational benefit and serving to strengthen instructional relevance. Review of the comments provided in support of survey responses indicated strong support for implementation of the flipped classroom model.

Flipped learning methodology was clearly viewed by students as a creative idea that could be successfully implemented in their university. Many positives were identified relating to this innovative concept. This didactic strategy was viewed as a means to improve and strengthen the university experience. Students clearly felt that flipped learning methodology holds potential usefulness for enhancing their participation in the learning process. Instructors are encouraged to examine this methodology as a means of engaging students at a higher level to strengthen problem-solving skills and foster creative thinking through empowered discussion and problem solving.

The respondents' negative comments indicate some concerns of reduced student-professor interaction and increased self-study load. These concerns are valid and can be addressed through proper students' guidance, advising, and seminars. For example, the instructor can interact with the student on line or dedicate the first ten minutes of the lecture to briefly explain the concept and answer students' questions. Moreover, faculty training and support for the flipped learning model is very important to ensure the acceptance and success of this method among students and faculty.

Finally, one cannot help but be impressed by the tech-savvy nature of today's student population. Clearly, the utilization of technology in the didactic setting ensures students that the learning experience is relevant and up-to-date. An old adage might be appropriate, "When in Rome, do as the Romans do!" When serving tech-savvy students, professors and instructors are well advised to evidence an equal or greater level of technical proficiency than their students.

This research is intended to guide practice and encourage further research on the topic. Both quantitative and qualitative studies should be applied to examine the potential efficacy of the flipped classroom model and to identify strategies for successful implementation at the higher education level.

\section{References}

Beesley, A., \& Apthorp, H. (Eds.). (2010). Classroom instruction that works, second edition: Research report. Denver, CO: McRel.

Fisher, D., \& Waller, L. (2013). The $21^{\text {st }}$ century principal: A study of technology leadership and technology integration in Texas k-12 schools. The Global eLearning Journal, 2(4). Retrieved from http://www.theglobalelearningjournal.org/wp-content/uploads/2010/11/Fisher-Article1.pdf

Flipped Learning Network. (2013). Flipped Learning and Higher Education. Retrieved from http://flippedlearning.org/domain/41

Greenberg, B., Medlock, L., \& Stephens, D. (2011). Blend my learning: Lessons from a blended learning pilot. Oakland, CA: Envison Schools, Google, \& Stanford University D. School. Retrieved from http://blendmylearning.files.wordpress.com/2011/12/lessons-learned-from-a-blended-learning-pilot4.pdf

Hamre, B. K., \& Pianta, R. C. (2005). Can instructional and emotional support in the first-grade classroom make a difference for children at risk of school failure? Child Development, 76(5) 949-967. http://dx.doi.org/10.1111/j.1467-8624.2005.00889.x

Hattie, J. (2008). Visible learning: A synthesis of over 800 meta-analyses relating to achievement. New York: Routledge.

Lumadue, R., Waller, L., Hendricks, L., \& Lumadue, R. (2012). The mobile classroom at cross purposes with higher education: Pros and cons; Do's and don'ts. FOCUS on Colleges, Universities, and Schools, 6(1).

Lumadue, R., \& Waller, L. (2013). Educational Research Today (1st ed.). Cupertino, CA: Apple iTunes Connect. Retrieved from https://itunes.apple.com/us/book/educational-research-today/id691632696?mt=11

Medina, J. (2008). Brain rules: 12 principles for surviving and thriving at work, home, and school. Seattle, WA: Pear Press.

University of Southern California. (2015). Retrieved from https://learningdesign.usc.edu/teach/strategies/theinverted-classroom/ 
Waller, L., \& Lumadue, R. (2011). There's an (Educational) app for that?: M-learning across device platforms. Academic Leadership, 9(3).

Waller, L., \& Lumadue, R. (2013). Factor Analysis (1st ed.). Cupertino, CA: Apple iTunes Connect. Retrieved from https://itunes.apple.com/us/book/factor-analysis/id656956844?1s=1

\section{Copyrights}

Copyright for this article is retained by the author(s), with first publication rights granted to the journal.

This is an open-access article distributed under the terms and conditions of the Creative Commons Attribution license (http://creativecommons.org/licenses/by/3.0/). 